\title{
Association of Cytotoxic T-Lymphocyte Antigen-4 (CTLA4) Gene and CD80 Expression in Children with Idiopathic Nephrotic Syndrome
}

\author{
Amarjeet Mehta ${ }^{1}$ \\ Received: 13 September 2018 / Accepted: 24 September 2018 / Published online: 16 October 2018 \\ (C) Dr. K C Chaudhuri Foundation 2018
}

The exact pathogenesis of minimal change disease (MCD) in childhood nephrotic syndrome is still unknown. Disorder of Tcell functions altering the glomerular permeability, causing proteinuria has been proposed by Shalhoub [1]. Subsequently it was thought that it is due to podocytopathy and result of 'two-hit' phenomenon; firstly, over expression of $\mathrm{CD} 80$ on the podocytes following release of cytokines due to interleukins and viral infections and secondly dysregulation because of impaired Cytotoxic T-Lymphocyte Antigen-4 (CTLA4) gene expression. The CTLA4 modifies ongoing immune injury by blocking CD80-CD28 interaction and acts as a negative regulator of CD80 [2]. Increased CD80 excretion in urine of patients in relapse has been found previously and particularly in minimal change disease (MCD) than focal segmental glomerulosclerosis (FSGS) [3].

The G-allele in position +49 of exon 1 of CTLA4 gene has been shown to affect the CTLA4-driven downregulation of T-cell activation. The study by Mishra et al. [4] published in this volume of journal has attempted to find out the relationship of CTLA4 gene expression and its excretion in soluble form in urine of children with idiopathic nephrotic syndrome. As such frequency of both homozygous GG genotype and $\mathrm{G}$ allele did not show any close association in patients with nephrotic syndrome which may be due to small population studied. However, the sCTLA4 level was significantly increased in patients of MCD in comparison to controls and FSGS cases. Spink et al. [5] earlier reported association of +49GG genotype with significantly higher risk for MCD, FSGS and membra-

Amarjeet Mehta

dramarjeetmehta@yahoo.com

1 Division of Pediatric Nephrology, Department of Pediatrics, SMS Medical College, Jaipur, Rajasthan, India nous nephropathy in adult population. Further, Ohl et al. [6] in their study on pediatric population observed that GG genotype and $G$ allele were significantly associated with risk of MCD. Similarly, single nucleotide polymorphism at $-318 \mathrm{C} / \mathrm{T}$ region of CTLA4 gene has also been reported to affect CTLA4 expression. Thus, overall evidence suggests the relationship of CTLA4-CD80 axis in causation of podocytopathy and occurrence of proteinuria. Therefore, it appears prudent to use drug like Abatacept (modified CTLA4-Ig), a specific CD80 antagonist, which can reduce proteinuria in treatment resistant nephrotic syndrome patients in future.

\section{Compliance with Ethical Standards}

Conflict of Interest None.

\section{References}

1. Shalhoub RJ. Pathogenesis of lipoid nephrosis: a disorder of T-cell function. Lancet. 1974;2:556-60.

2. Karandikar NJ, Vanderlugt CL, Walunas TL, Miller SD, Bluestone JA. CTLA-4: a negative regulator of autoimmune disease. J Exp Med. 1996;184:783-8.

3. Garin EH, Mu W, Arthur JM, et al. Urinary CD80 is elevated in minimal change disease but not in focal segmental glomerulosclerosis. Kidney Int. 2010;78:296-302.

4. Mishra OP, Chhabra P, Narayan G, et al. Cytotoxic T- Lymphocyte Antigen-4 (CTLA4) gene expression and urinary CTLA4 levels in children with idiopathic nephrotic syndrome. Indian J Pediatr. 2018. https://doi.org/10.1007/s12098-018-2734-9.

5. Spink C, Stege G, Tenbrock K, Harendza S. The CTLA-4 +49 GG genotype is associated with susceptibility for nephrotic kidney diseases. Nephrol Dial Transplant. 2013;28: 2800-5.

6. Ohl K, Eberhardt C, Spink C, et al. CTLA4 polymorphisms in minimal change nephrotic syndrome in children: a case-control study. Am J Kidney Dis. 2014;63:1074-5. 